Revista Destaques Acadêmicos, Lajeado, v. 11, n. 2, 2019. ISSN 2176-3070

DOI: http://dx.doi.org/10.22410/issn.2176-3070.v11i2a2019.2236

http://www.univates.br/revistas

\title{
MULHERES E HOMENS NO CAMPO DA CAPOEIRA: DESIGUALDADE DE GÊNERO NA REVISTA PRATICANDO CAPOEIRA
}

\author{
Jeferson do Nascimento Machado ${ }^{1}$
}

Resumo: Compreendendo que a Capoeira, ao longo de sua trajetória, tem sido uma prática de predominância masculina e que a tradição oral narra uma história masculina, buscou-se neste artigo, dar a ver como essas tradições se reproduziram na revista Praticando Capoeira, através do tratamento desigual entre os gêneros relativa aos espaços designados às mulheres e homens. Para tanto, nosso estudo tomou o arranjo dos conteúdos de algumas edições da revistas Praticando Capoeira (conjunto fotográfico, seções de entrevistas, textos temáticos, capas, etc.) e as organizou em tabelas e gráficos, de modo à demostrar a desigual distribuição dos espaços conferidos a mulheres e homens. A partir desses dados realizamos uma discussão acerca da desigualdade de gênero presentes na capoeira, tendo como alicerce teórico Pierre Bourdieu (2012) e seu estudo acerca da dominação masculina, o que nos levou a concluir que a dominação masculina está interiorizada, tanto nos homens quanto nas mulheres, e que ela se reproduz socialmente, entre outras formas, nas revistas de Capoeira.

Palavras-chave: Revista Praticando Capoeira. Desigualdade de gênero. Dominação masculina.

\section{INTRODUÇÃO}

Os estudos sobre a capoeira, que levem em conta a categoria de gênero ${ }^{2}$, começaram a ser realizados recentemente ${ }^{3}$ e, por conseguinte, a produção

1 Licenciado em História pela Universidade Estadual do Centro-Oeste (UNICENTRO) e mestrando em História pelo Programa de Pós-Graduação Stricto Sensu em História (PPGH/ UNICENTRO). E-mail: jefersondonascimentomachado@gmail.com

2 Entendemos gênero na maneira que aponta Scott: como categoria que engloba as relações sociais com base nas diferenças entre os sexos. Ou seja, gênero é a construção social que atribui papeis diferenciados a homens e mulheres. Para obter maiores informações ler: SCOTT, J. Gênero: uma categoria útil de análise histórica. Educação e Realidade. Porto Alegre, v.20, n.2, p.71-99, jul/dez, 1995.

3 A título de exemplo podemos citar os estudos realizados por Souza (2010) e Bezerra (2010). 
acadêmica sobre o assunto ainda é insuficiente do ponto de vista do acúmulo intelectual para o estabelecimento de uma teoria ${ }^{4}$. $\mathrm{O}$ mesmo pode ser dito acerca das revistas de capoeira. Portanto, visto a insuficiência da massa crítica relacionada à categoria de gênero aplicada aos estudo sobre a capoeira e o trabalho com as revistas, este estudo ${ }^{5}$ se insere no intuito de fornecer mais material para o acúmulo de massa crítica.

Além disso, este estudo busca contribuir para às lutas das mulheres, sobretudo às mulheres capoeiristas, pois entendemos que ao evidenciarmos a dominação masculina e os mecanismo de sua sustentação, colaboramos para que esse domínio seja desnaturalizado, conforme sugere Bourdieu (2012). Em outras palavras, dar a ver a dominação masculina no campo da capoeira e desnaturalizá-la, contribuirá para a emancipação das mulheres na capoeira, alterando o próprio campo da capoeira, tornando-a mais libertária.

Dito isso, salientamos que este estudo faz uma abordagem sobre as desigualdades de gênero presente na revista Praticando Capoeira, bem como discute sua relação dialética com a realidade, levando em conta que a revista é catalisadora do contexto social no qual está inserida e também difusora de representações sociais. Compreendendo que a capoeira, ao longo da história, tem sido uma prática de hegemonia masculina (SOUZA, 2010) e que a tradição oral narra uma história onde predominam os homens, buscaremos verificar como essas tradições se reproduzem nas revistas através duma maior valorização dos capoeiristas homens em relação as capoeirista mulheres. Para tanto, nosso estudo tomou quatro revista Praticando Capoeira, publicadas entre 2002 e 2008, no conjunto das fotografias ali distribuídas e as seções de entrevistas e, a partir delas, realizou uma abordagem comparativa sobre os espaços ${ }^{6}$ destinados as mulheres e aos homens. Tomamos Pierre Bourdieu (2012) como alicerce teórico de nossa abordagem, sobretudo seu conceito de campo social, que aplicamos a Capoeira, e o seu estudo acerca da dominação masculina, que aplicamos na discussão sobre a desigualdade de gênero na Capoeira.

4 Teoria aqui é tomada no sentido marxiano, conforme sugere Paulo Netto, no qual estabelece que teoria seja uma reprodução ideal (no nível subjetivo do pesquisador) do movimento real do seu objeto de estudo. Para obter mais informações ler o livro: NETTO, J P. Introdução ao estudo do método de Marx. São Paulo: Expressão Popular, 2011.

5 Este artigo foi resultado das discussões realizadas durante a disciplina de "Tópicos Especiais em: gênero e pesquisa em história", oferecida como disciplina optativa no Programa de Pós-Graduação em História da Universidade Estadual do Centro-Oeste, no ano de 2017, e ministrada pela Professora Nadia Maria Guariza. Também foi resultante da apresentação parcial do texto no evento Conversas Latinas em Comunicação - Memória e Audiovisual de 2017, realizado nesta mesma universidade.

6 A abordagem aqui realizada é relativa aos espaços e não especificamente os conteúdos. 


\section{Exposição dos principais conceitos utilizados neste estudo}

O conceito de campo social, para Pierre Bourdieu(2003), é o espaço abstrato, permeado por regras socialmente adquiridas (também chamado pelo autor de habitus ${ }^{7}$ ) onde estão distribuídos agentes sociais e instituições (com diferentes acúmulos de capitais simbólicos), que lutam entre si na busca de melhores posições dentro deste mesmo espaço. Aqui, partimos da concepção de que a capoeira é um campo, tal como pondera Bourdieu, pois partimos da noção que na capoeira existem agentes (capoeiristas) e instituições (grupos de capoeira e associações) que ocupam posições diferenciadas dentro desse espaço (diferença de graduação, diferença de gênero, etc.) e lutam por troféus e melhores posições dentro do campo (de tornar-se professor, tornar-se mestre, etc).

A questão da dominação masculina, que utilizamos para discutir a desigualdade de gênero, foi desenvolvia por Bourdieu (2003) em sua obra $A$ Dominação Masculina. Nesta obra o autor aborda a partir de seus estudos da sociedade Cabíla, que a dominação masculina é uma expressão particular da violência simbólica e que ela se justifica por meio da naturalização e interiorização das diferenças socialmente construídas, fazendo com que os papeis sociais atribuídos ao masculino e feminino sejam compreendidas como diferenças inscritas na natureza biológica dos sexos. Ou, nas palavras de Bourdieu,

a diferença biológica entre os sexos, isto é, entre o corpo masculino e o corpo feminino, e, especificamente, a diferença anatômica entre os órgãos sexuais, pode assim ser vista como justificativa natural da diferença socialmente construída entre os gêneros e, principalmente, da divisão social do trabalho. (BOURDIEU, 2012, p.20)

Essa naturalização é interiorizada por meio da linguagem, nos modos de pensar, de comportar-se, no qual a mulher é representada na figura de dominada e o homem na figura de dominante. Assim sendo, abordaremos a revista Praticando Capoeira de modo a dar a ver a violência simbólica, da dominação masculina, que opera silenciosamente no campo da Capoeira por meio da desigual distribuição dos espaços designados às mulheres e homens.

\section{EXPOSIÇÃO E ABORDAGEM DOS DADOS}

Nesta parte buscaremos expor os dados, mostrando a partir de tabelas e gráficos, como os espaços dedicados às mulheres e homens nas revistas Praticando Capoeira, são desigualmente distribuídos. Os dados aqui ponderados

7 Habitus é utilizado por Pierre Bourdieu como um esquema de interiorização das regras do campo, de reflexão sobre essas regras e de ação sobre este mesmo campo. 
se referem ao acervo fotográfico apresentado pelas revistas, as capas e as entrevista. Junto das pontuações quantitativas, faremos uma discussão qualitativa sobre esses dados, buscando discutir o papel da revista enquanto vinculadora e catalisadora de representações do mundo social onde está inserida.

\section{A capa}

A capa é a primeira interação que o leitor tem com a revista. Na banca de jornal ou na livraria, o consumidor compra o produto pelo conteúdo de capa, e exatamente por isso, as capas de revistas tentam destacar aquilo que há de mais impressionante e chamativo, levando em conta as expectativas de seus consumidores.

As quatro capas da revista Praticando Capoeira, aqui analisadas, são hegemonicamente masculina, tirando uma rara exceção na qual aparece uma capoeirista mulher entre muitos capoeiristas homens. A seguir apontaremos descritivamente, cada uma delas.

O destaque da capa da revista do Ano II - $\mathrm{N}^{\circ} 19$, publicada em 2002, se resume em 5 capoeiristas (entre eles Mestre Acordeon) jogando Capoeira na escada do Teatro Municipal de São Paulo. Não há mulheres na Capa.

A revista Ano II - No25, publicada em 2004, tem como destaque de capa o mestrando Morcego, do Grupo Abadá e Mestre Suassuna. A capa é formada por duas fotografias recortadas na diagonal, na qual aparece na parte de cima Mestre Morcego, com o braço aberto em sinal de "chamado", e seu grupo e logo abaixo, Mestre Suassuna, que está em pé tocando berimbau, e seu grupo. Somente umas das fotografias (a que destaca mestre Morcego) possuem mulheres entre o capoeirista, porém aparecem sem nenhum destaque. Uma delas aparece cortada acima da cintura e outra mostra somente a metade do seu rosto, que se esconde atrás de um dos capoeiristas. No geral, a capa da revista é representada por capoeiristas homens.

Revista Ano IV - No 43, publicada em 2008, contém duas fotografias, sendo que uma delas está no centro e a outra está sobreposta ao lado direito superior da fotografia central. As fotografias são de dois mestres, mestre Leopoldina (em destaque) e Mestre Barrão. Essa capa também não apresenta mulheres.

Revista Ano III - No 29, de publicação do ano 2005, é formada por apenas uma fotografia, que é do mestre Moraes, do (Grupo Capoeira Angola Pelourinho). Novamente vemos uma capa sem mulheres.

Como visto nos parágrafos acima, as capas dessas quatro revistas são hegemonicamente masculinas, não dando visibilidade as mulheres capoeiristas. Se nas entrevistas e nas fotografias no interior revista as mulheres aparecem, mesmo que de forma secundária, na capa elas são totalmente ignoradas. 
Desse modo, uma revista como a Praticando Capoeira, que tem como clientes capoeiristas, que são herdeiros de uma tradição masculina e que esperam uma revista de conteúdo correspondente, reproduzirão em suas capas os valores, ideias e representações atreladas a este universo e correspondente às expectativas. Assim sendo, a estratégia do marketing adotada, responde o mais esperado e reproduz o mesmo status quo.

\section{A Fotografia}

A segunda interação que o leitor tem ao folhear alguma revista, são as imagens e, por isso, todo periódico investe intensamente nas fotografias. E com a revista Praticando Capoeira não seria diferente, assim sendo, o corpo editorial se empenhou na construção de rico acervo fotográfico, no qual expõe rodas, fotografias de capoeiristas, etc. As fotografias, em grande parte, foram feitas por Letícia de Carvalho, ou são partes do acervo pessoal dos mestres e grupos de capoeira, e todas elas passaram pelas mãos de Rodney Marcelo Borges, que é o diagramador da revista e trabalha para melhorar a qualidade das fotografias.

Essas imagens fotográficas captadas e redistribuídas nas revistas, passaram pelos óculos da tradição da Capoeira, na qual narra e enfatiza os personagens masculinos mais do que as femininas (por exemplo, personagens como Maria Felipa de oliveira não são tratadas com a mesma ênfase do que Besouro de Mangangá). Em suma, as fotografias foram submetidas à estrutura da dominação masculina, a qual é catalisada inconscientemente e reproduzida dentro do campo da Capoeira, e dessa forma, (re) atualiza a estrutura de dominação. Toda essa operação é realizada perante uma violência simbólica, por meio do conjunto fotográfico. Entenda-se violência simbólica como

Violência suave, insensível, invisível a suas próprias vítimas, que se exerce essencialmente pelas vias puramente simbólicas da comunicação e do conhecimento, ou, mais precisamente, do desconhecimento ou, em última instância, do sentimento. (BOURDIEU, 2012, p.7)

A dominação, como aponta Bourdieu (2012), é fruto de uma ação de violência simbólica interiorizada e reproduzida por ambos os sexos. A dominação é relacional, sendo que as próprias mulheres a reproduzem sem perceberem-se vítimas de um processo de dominação, pois a realidade que é cultural aparece como natural.

Dentro dessa perspectiva, notamos que há uma violência simbólica no tratamento fotográfico, pois percebemos uma desigualdade entre os gêneros nos acervos produzidos. Como podemos visualizar na Tabela 1, as quatro revistas aqui analisadas possuem um total fotográfico de 197 fotos, porém, destas, 97 são fotografias unicamente de homens e apenas 11 exclusivamente de mulheres. Além do mais, nota-se que as fotografias que deram destaque 
às mulheres (onde estão somente elas, estão em maior número ou aparecem jogando Capoeira) foram apenas 35 , sendo que 172 deram destaque aos homens. Também, conforme podemos ver no gráfico 1 entre os anos de 2002 e 2008, a abordagem fotográfica permaneceu constante, praticamente sem oscilações, prevalecendo sempre a fotografia masculina.

Esses dados nos indicam a violência simbólica que as mulheres sofrem na capoeira, por meio do constante silenciamento e reprodução da mulher como figura secundária. A seleção das fotografias, organizadas pelo corpo editorial, reproduzem o discurso da tradição, pois enfatizam mais os personagens masculinos.

TABELA 1 - Relação fotográfica de praticantes masculinos e femininos vinculadas na revista Praticando Capoeira

\begin{tabular}{l|l|l|l|l|l}
\hline & $\begin{array}{l}\text { Revista } \\
\text { Ano II - No } \\
19 \text { (ano de } \\
2002)\end{array}$ & $\begin{array}{l}\text { Revista } \\
\text { Ano II - } \\
\mathbf{N}^{\circ} 25 \\
\text { (ano de } \\
2004)\end{array}$ & $\begin{array}{l}\text { Revista } \\
\text { III - No 29 } \\
\text { (ano de } \\
2005)\end{array}$ & $\begin{array}{l}\text { Revista Ano } \\
\text { IV - No 43 } \\
\text { (ano de 2008) }\end{array}$ & Total \\
\hline Total de fotografias & 50 & 54 & 44 & 49 & 197 \\
\hline $\begin{array}{l}\text { Fotografias que destacaram as } \\
\text { mulheres }\end{array}$ & 9 & 13 & 5 & 8 & 35 \\
\hline $\begin{array}{l}\text { Fotografias que destacaram } \\
\text { os homens }\end{array}$ & 41 & 48 & 41 & 42 & 172 \\
\hline $\begin{array}{l}\text { Fotografias que apareceram } \\
\text { somente homens }\end{array}$ & 25 & 24 & 22 & 26 & 97 \\
\hline $\begin{array}{l}\text { Fotografias que apareceram } \\
\text { somente mulheres }\end{array}$ & 4 & 3 & 2 & 2 & 11 \\
\hline
\end{tabular}

Esta tabela não inclui as fotografias de capa (que será discutida separadamente), contracapa, índice, página do leitor e as páginas publicitárias da revista.

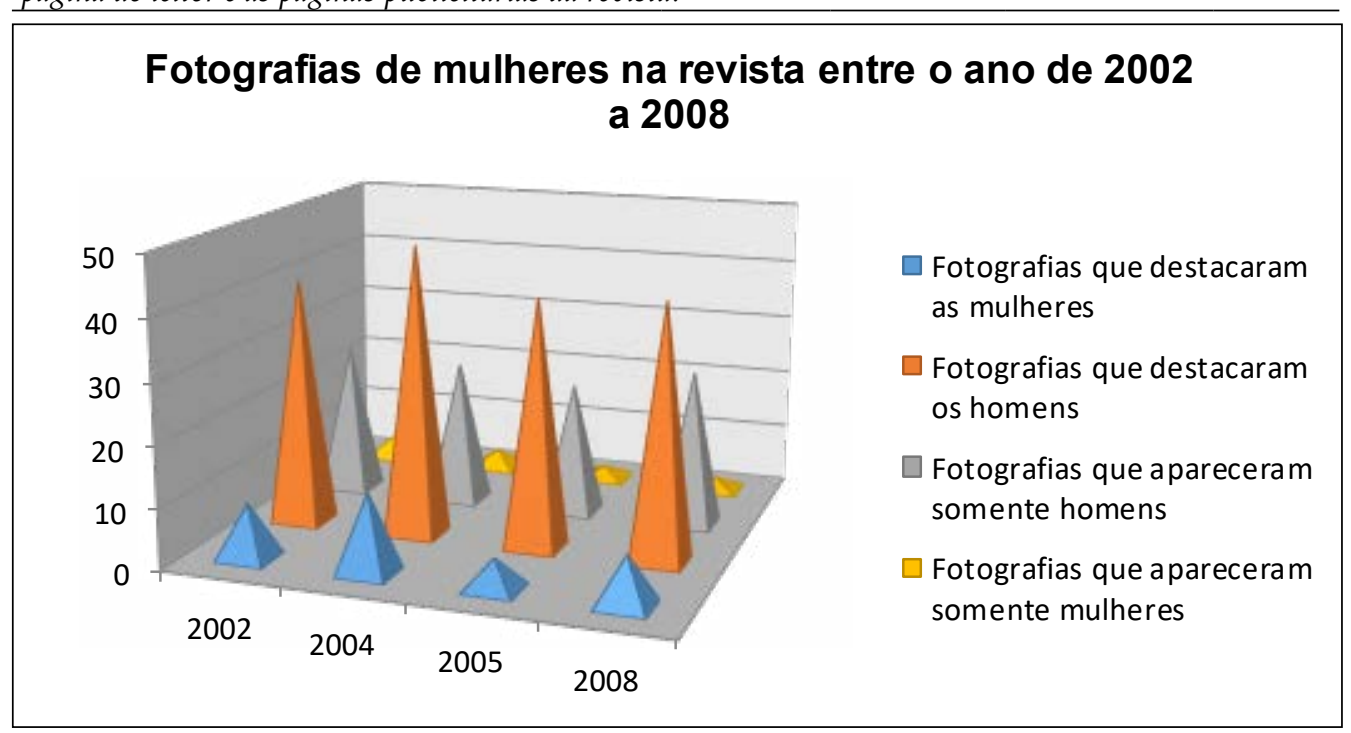




\section{Entrevistas}

As entrevistas vinculadas a revista Praticando Capoeira, quase todas realizadas por Letícia Carvalho, buscam entrevistar mestres conceituados e lançar perguntas relacionadas à trajetória pessoal dos mestres e seus grupos, bem como mostrar a opinião dos mestres sobre o campo da capoeira. Porém, mesmo existindo uma série de professoras e mestras de Capoeira, a revista optou por dedicar a maior parte das entrevistas com capoeirista homens. Isso pode ser mais bem visualizado na Tabela 2, na qual nota-se que das 21 entrevista, 17 foram realizadas com homens e apenas 4 com mulheres.

TABELA 2 - Entrevistas vinculadas à revista

\begin{tabular}{l|l|l|l|l|l}
\hline & $\begin{array}{l}\text { Revista } \\
\text { Ano II - } \\
N^{\circ} \text { 19 (ano } \\
\text { de 2002) }\end{array}$ & $\begin{array}{l}\text { Revista } \\
\text { Ano II - } \\
N^{\circ} \text { 25 (ano } \\
\text { de } \\
\text { 2004) }\end{array}$ & $\begin{array}{l}\text { Revista III - } \\
\mathbf{N}^{\circ} \text { 29 (ano de } \\
\text { 2005) }\end{array}$ & $\begin{array}{l}\text { Revista } \\
\text { Ano IV - No } \\
\text { 43 (ano de } \\
\text { 2008) }\end{array}$ & Total \\
\hline Total de entrevista & 5 & 5 & 4 & 7 & 21 \\
\hline $\begin{array}{l}\text { Entrevistas que destacaram } \\
\text { as mulheres }\end{array}$ & 1 & 1 & 1 & 1 & 4 \\
\hline $\begin{array}{l}\text { Entrevistas que destacaram } \\
\text { os homens }\end{array}$ & 4 & 4 & 3 & 6 & 17 \\
\hline
\end{tabular}

Visto os dados acima e o elevado percentual de entrevistas dedicadas aos homens, vale observar que o leitor da revista interioriza essa sobrevalorização dos homens capoeiristas e atualiza seus esquemas de classificação e de ação sobre o campo (habitus), levando a reafirmação da dominação masculina na capoeira. No entanto, é necessário colocar que essa interiorização e reprodução são realizadas inconscientemente e que o domínio masculino exercido na capoeira e articulado na revista se faz, não por meio de um ato de dominação direita, na qual uma série de agentes domina outro, mas por efeitos indiretos nascido das complexidades estrutural do próprio campo (BOURDIEU, 1996).

\section{CONSIDERAÇÕES FINAIS}

Pela análise das quatro revistas da Praticando Capoeira, realizada nos capítulos anteriores, verificou-se que existe uma grande desigualdade de gênero no tratamento dado aos capoeiristas, porque a maior parte da revista é dedicada a capoeiristas homens. Também se verificou que as desigualdades de gênero existentes nas revistas possuem uma relação dialética com a realidade social da prática da Capoeira e, assim sendo, ela funciona como catalisadora da estrutura do campo da Capoeira e difusora dessa mesma estrutura.

Essa estrutura masculina da capoeira é reproduzida nas revistas e interiorizada pelos seus leitores, os quais reafirmam seu esquema de percepção e classificação da capoeira, que prioriza o sexo masculino. 
Contudo, vale salientar que esta abordagem, longe de pretender um engessamento da mudança, por meio dos apontamentos acerca da estrutura e como ela se reproduz, buscou evidenciar a desigualdade de gênero e a dominação masculina para que os próprios capoeiristas, homens e mulheres, passem a notar aquilo que acontece de forma oculta e que, a partir disso, consigam refletir e agir no intuído de diminuir as desigualdades de gêneros, levando a capoeira a se encontrar com seu próprio ideal fundador, que é a liberdade.

\section{REFERÊNCIAS}

BEZERRA, P. N. R. Tem mulher na roda? Perspectivas feministas sobre relações de gênero e feminilidade na capoeira. Pernambuco: ANPHU, 2010.

BOURDIEU, P. A Dominação Masculina. Rio de Janeiro: Bertrand Brasil, 2012

BOURDIEU, P. Questões de Sociologia. Lisboa: Fim de Século - Edições, Sociedade Unipessoal, 2003. 288 p.

BOURDIEU, P. Razões Práticas obre a Teoria da Ação. Campinas: Papirus, 1996. 224 p.

LEITÃO, Luís António Ferreira. Analise dos discursos femininos no contexto da capoeira na revista "Praticando Capoeira. 2004, 88 p. Dissertação (apresentada com vista à obtenção do grau de licenciado em Ciências do Desporto e Educação Física, pela Universidade de Coimbra.) Coimbra: Universidade de Coimbra, 2004.

NETTO, J P. Introdução ao estudo do método de Marx. São Paulo: Expressão Popular, 2011.

PIRES, A. L. C. S. A Capoeira na Bahia de Todos os Santos - Um Estudo Sobre a Cultura e Classes Trabalhadoras (1890 - 1937). Tocantins: Grafset Editora ltda e Núcleo de Estudos Afro-Brasileiros, 2004.

SCOTT, J. Gênero: uma categoria útil de análise histórica. Educação e Realidade. Porto Alegre, v.20, n.2, p.71-99, jul/dez, 1995.

SOUZA, E.G.R.S. Capoeira: sua História e as Relações de Gênero. Rio de Janeiro: ANPHU, 2010. 


\section{ANEXOS}
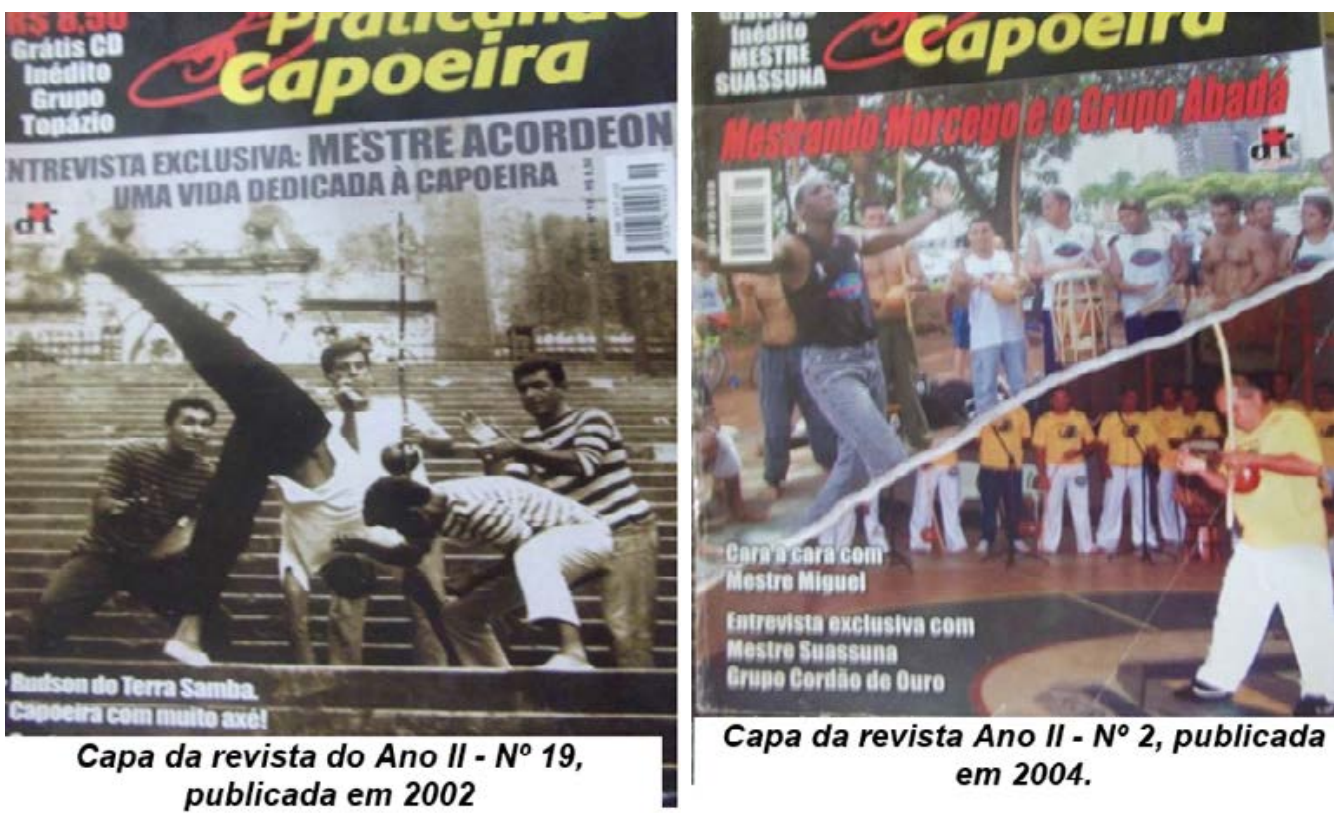

Capa da revista Ano II - $N^{\circ} 2$, publicada em 2004.

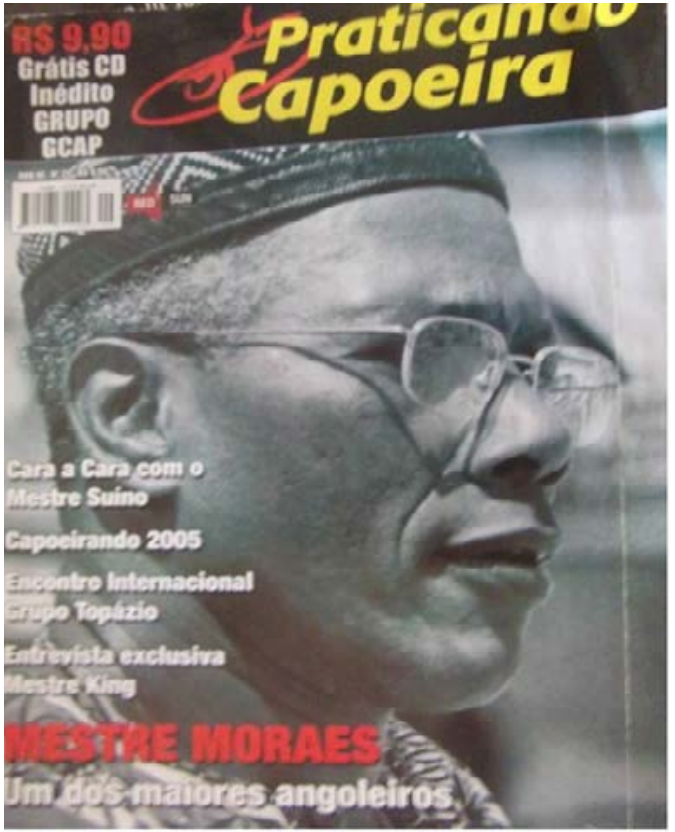

Capa da revista III - $N^{\circ} 29$, publicada em de 2005

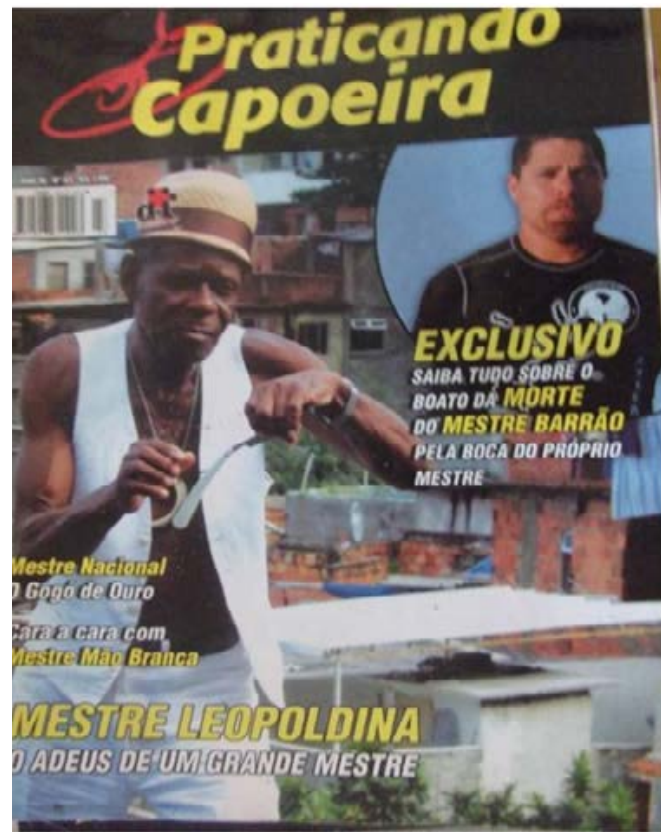

Capa da revista Ano $I V-N^{\circ} 43$, publicada em 2008 